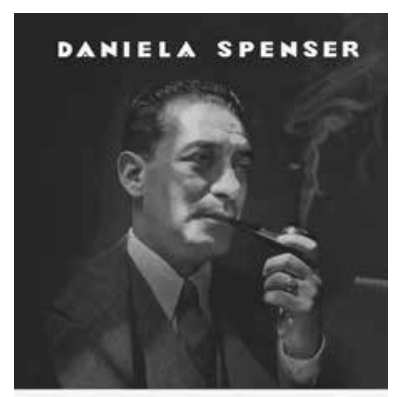

EN COMBATE

LA VIDA DE LOMBARDO TOLEDANO DEBATE
- En combate. La vida de Lombardo

Toledano

DANiela Spenser, 2018

Debate-Penguin Random House, México

\title{
Lombardo, entre el combate y el debate
}

\author{
ALBERTO AZIZ NASSIF
}

Lombardo, between

Combat and Debate

ALberTO AzIZ NASSIF

Centro de Investigaciones y Estudios Superiores en Antropología SocialCiudad de México, México aziz@ciesas.edu.mx

Desacatos 59, enero-abril 2019, pp. 207-210
Una ventana hacia la historia del siglo Xx: del esplendor y el ocaso del antiguo régimen; de la Revolución mexicana y las transformaciones que ese conflicto efectuó sobre la sociedad; de la reconstrucción intelectual y social del país bajo nuevos parámetros, que incluyó el ascenso del movimiento obrero a la prominencia política, así como de la intervención obrera en la construcción y la consolidación del Estado; de la disputa por el rumbo de la nación en los convulsionados años 
treinta y la configuración de la izquierda política e ideológica de México. Su vida y su obra revelan las conexiones de México con el mundo durante la Segunda Guerra Mundial y la Guerra Fría (p. 10).

Para responder a la pregunta tenemos que entender que Daniela escribió e investigó múltiples historias sobre el comunismo en México, partidos socialistas regionales, la Guerra Fría, hasta que llegó a Lombardo, una obra de madurez que preparó durante mucho tiempo y que le tomó al menos diez años escribir. Es una obra densa, en la que no se pierde de vista que el personaje es un hombre complejo, con múltiples matices y facetas, inserto en contextos locales, nacionales e internacionales de mucha relevancia. Este libro, además, es un triunfo de Daniela sobre el sistema académico actual de puntos y evaluaciones, que incrementa la productividad de corto plazo, sin cuidar la calidad y las obras de largo alcance. La calidad de este libro es un presupuesto básico. Su muy documentada bibliografía es fruto de una revisión amplia en archivos de México, Estados Unidos, Rusia, Inglaterra, Holanda y Suiza; incluye una revisión exhaustiva de la bibliografía, de la obra de Lombardo y varias entrevistas a informantes clave.

\section{¿Quién fue Lombardo?}

A lo largo de la obra se presenta un personaje multifacético, que a la vez sostuvo ideas fuerza que lo acompañaron toda su vida. De pronto parece que es un dogmático del marxismo soviético, pero al mismo tiempo es un soñador con ideas propias que no se acomodó en sus logros institucionales y buscó de forma incesante proyectar sus objetivos dentro y fuera del país. Tuvo el mérito de ubicarse en un amplio mirador internacional, que lo ponía por encima de sus correligionarios atrapados en lo local y la grilla casera.
Fue el gran líder del movimiento obrero, que logró la creación de importantes centrales obreras en el momento de esplendor de las luchas de los trabajadores en el México posrevolucionario, con el cardenismo como el punto más alto de realización de los postulados de la Revolución mexicana. Al mismo tiempo, fue el dirigente con un matiz idealista o ingenuo que dejaba la política local para ir en búsqueda de horizontes internacionales, viajero incansable del internacionalismo proletario. Lombardo fue el gran intelectual de izquierda, marxista, pero también el acompañante imprescindible de los presidentes de la República, el vocero de las luchas obreras y el protector del Estado mexicano, cuando esas dos figuras fueron compatibles y cuando no.

Lombardo tuvo sus principios y sus dogmas. Fue el ejemplo más visible de lo que hace una ideología que se entiende como científica, pero también fue un caso en el que una idea fuerza, la lucha contra el imperialismo, fue su guía de acción y pensamiento. Nunca perdió de vista la necesidad de apoyar al Estado mexicano, por encima de cualquier amenaza que intentara desafiarlo. En ese orden de jerarquías, excusó o miró hacia otro lado ante los fraudes sistemáticos, las alianzas orgánicas con el priismo, los apoyos incondicionales al presidente, así fueran Cárdenas o Díaz Ordaz. Justificó a Alemán y la represión a los sindicatos independientes con tal de lograr la industrialización del país, porque era la consigna del desarrollo de las fuerzas productivas que planteaba cierto marxismo.

El polémico líder, intelectual orgánico, fue un gran orador y estratega, creador de instituciones educativas, corporaciones obreras y campesinas y partidos políticos. Al mismo tiempo, fue el cándido intelectual que le dejó el puesto al zorro de Fidel Velázquez, que terminó por expulsarlo de la Confederación de Trabajadores de México (CTM) y se quedó con el control de las organizaciones obreras durante décadas, hasta su muerte. El Lombardo que organizaba corporaciones puso por delante sus 
afanes de socialista, pero quién sabe si en algún momento calculó que su voluntad de abarcar cada vez más espacios de poder se topaba con los núcleos duros del poder de las coaliciones que dominaron el mundo corporativo y político. Pensó que podía crear una nueva CTM y ser más grande, y se equivocó. Pensó que podía crear un partido político y dejar atrás al Partido Revolucionario Institucional (PRI) y no lo logró. Pensó que el fraude era algo menor, porque la democracia era "burguesa" y lo importante era el fin superior de alcanzar el socialismo.

El Partido Popular (PP), después Partido Popular Socialista (PPS), de su creación, acabó por convertirse en un apéndice, aliado casi incondicional del PRI, porque así lo mandaba o lo interpretaba el marxismo de Lombardo. Pensó que podía ser presidente, y como dijo Fidel Velázquez, el que se mueve no sale en la foto. Si algo hizo Lombardo en todos esos años, antes de la Segunda Guerra Mundial, durante la Guerra Fría y después, fue moverse, sin dejar de estar en combate.

El marxista, orgullo de los soviéticos y estalinistas, se quedó con sus referencias y así fue envejeciendo. Poco a poco el país cambió y los aires revolucionarios que soplaron con fuerza durante el cardenismo quedaron en el pasado. De la alianza a la subordinación, de la estrategia de organización al corporativismo vertical, de los logros populares al sometimiento de los intereses obreros y campesinos, Lombardo permaneció leal y fue muy útil para el régimen de la Revolución mexicana, hasta su muerte.

El intelectual sensible y viajero permanente dejó de entender los cambios de un mundo que ya no cabía en la contradicción entre imperialismo y socialismo. Así como con el fascismo, que usaba la brocha gorda, dice Daniela, Lombardo terminó sus días con una visión equivocada de lo que fue el movimiento del 68 en varios países, al que condenó con brocha gorda y miopía amplia. Desde el anquilosamiento de un marxismo que se hizo rancio, condenó la movilización estudiantil en el mayo parisino, la primavera de Praga y el 68 en México, y se mantuvo del lado del poder y el diazordacismo.

\section{¿Qué herencia deja Lombardo? ¿Hay claves en su trayectoria y pensamiento para entender el México actual?}

Lombardo fue parte de esa elite intelectual vinculada al poder ascendente posrevolucionario. Formó parte del grupo que construyó el siglo Xx mexicano, con Pedro Henríquez Ureña, Alfonso Caso, Daniel Cosío Villegas y otros. Su larga trayectoria corre desde la política de los poderosos y las luchas que van de Obregón a Calles, el Maximato, el cardenismo, de Ávila Camacho a Alemán, y de Ruiz Cortines a López Mateos, hasta llegar a Díaz Ordaz. Su constante fue el convencimiento de que el Estado podía "redimir" a la población trabajadora - tuvo una veta religiosa en su marxismo-, hoy le dirían populista. La Unión Soviética dejó una huella permanente. Daniela cuenta el contraste que existió entre él y el líder inglés Citrine o el francés Gide en la percepción de la URSS. Mientras Lombardo hacía poesía, los otros eran muy críticos. Estuvo alineado con el cardenismo y así siguió con los demás presidentes.

La CTM y su evolución dejan ver cómo esas organizaciones se transformaron de ser la vanguardia del proletariado a ser una pieza de control de un modelo neoliberal. Con Cárdenas, a la izquierda; con Alemán, a la derecha; con Salinas fueron el pararrayos del ajuste, y con Peña, los saboteadores de una reforma laboral progresista.

Así, el Lombardo de la creación cetemista fue muy distinto del que apoyó a Díaz Ordaz. Con este personaje entendemos cómo en la izquierda mexicana contemporánea hay expresiones y reflejos que pasan por la política actual, hay herederos políticos, como el Partido Socialista de los Trabajadores (PST) en la década de 1970, el ferrocarril en la de 1980 y 
hoy partes del perredismo. También hay otras partes de la izquierda mexicana que reivindicaron las luchas autónomas y mantuvieron su distancia con el Estado, hasta la fecha, como el zapatismo. El cardenismo ha estado presente y se proyecta hasta la actualidad con legitimidad.

¡Vaya! El escenario y las piezas que explican este país han cambiado desde la muerte de Lombardo, que como el 68, cumplen 50 años. Se terminó el internacionalismo proletario, pero llegó el “otro mundo es posible”. Se acabó la Guerra Fría y llegó la globalización. Cambiaron los referentes, pero no hemos dejado atrás el lenguaje de la Guerra Fría y su confrontación bipolar. Ya no hablamos mucho de explotación, pero sigue existiendo. Hoy hablamos de desigualdad. Ya no mencionamos el imperialismo, pero las corporaciones internacionales siguen apropiándose de los recursos naturales, y el extractivismo y neoextractivismo son reales. Las izquierdas se han visto disminuidas en el mundo neoliberal, que ha incrementado la desigualdad a escala planetaria. Hoy las luchas populares son por los derechos humanos y el medio ambiente, y en medio de todo, la democracia dejó de ser burguesa y con las transiciones se volvió una suerte de utopía que hoy está siendo desarmada en todas partes. La resistencia es contra el neocolonialismo, el patriarcado, el neoextractivismo. Pues sí, en 50 años vimos la caída del Muro de Berlín, la desaparición de la URSS, la destrucción de Irak, el calentamiento global, el mundo de la financiarización, el terrorismo islámico, la caída de las Torres Gemelas, la llegada de Trump al poder como el más alto retroceso de una democracia y otros horrores.

En suma, qué lejos está Lombardo del México actual y qué cerca sigue todavía en los gestos de ciertas agrupaciones que se dicen de izquierda y sufren una suerte de trastorno bipolar, cuidan sus intereses, pero su discurso es de izquierda dura. Sin duda, este México que se ha girado con fuerza a la derecha, necesita recuperarse de los golpes y traumas que todos los días nos dan la corrupción que parece invencible, la impunidad que no tiene fin, la desigualdad que avanza, la pobreza que sólo se administra y la violencia que destruye nuestra seguridad mínima. Nos quedamos con la idea que animó la vida de Lombardo, quien a pesar de todo siempre estuvo En combate. D 